EXTENDED REPORT

\title{
Attitudes to early rheumatoid arthritis: changing patterns. Results of a survey
}

\author{
D Aletaha, G Eberl, V P K Nell, K P Machold, J S Smolen
}

Ann Rheum Dis 2004;63:1269-1275. doi: 10.1136/ard.2003.015131

See end of article for authors' affiliations

Correspondence to:

Dr D Aletaha, Division of

Rheumatology,

Department of Internal

Medicine III, University of

Vienna, Vienna General

Hospital, Waehringer

Guertel 18-20, A-1090

Vienna, Austria;

daniel.aletaha@

meduniwien.ac.at

Accepted

6 November 2003
Objective: To determine if rheumatologists have changed their views on diagnosis and treatment of early rheumatoid arthritis (RA).

Methods: Three consecutive questionnaires were sent out to international rheumatologists in 1997, 2000, and 2003. The following aspects of early RA were covered: definition; patient referral time; diagnostic means; follow up intervals; and treatment strategies. All initial participants who responded to at least one of the follow up surveys were included in the analysis.

Results: RA is now defined by a smaller number of affected joints (monarthritis: $9.8 \%$ respondents in 1997 $v 17.4 \%$ in 2003), and shorter symptom duration (<3 months: $65.5 \%$ in 1997 v $85.8 \%$ in 2003). Early referrals (<6 weeks) increased (8.9\% in 1997 v $17.4 \%$ in 2003). Serological test for diagnosis was mostly rheumatoid factor (100\% in 2003), but anti-CCP was already used by $17.4 \%$ in 2003 . Follow up of patients with early RA intensified (every 2 weeks: $16.1 \%$ in 1997 v $30.4 \%$ in 2003; every month: $47.8 \%$ in 2003 v 64.3\% in 1997). Treatment with disease modifying antirheumatic drugs (DMARDs) mainly comprised methotrexate, sulfasalazine, and antimalarial drugs. Leflunomide was among the two favourite DMARDs of $10.9 \%$ in 2003, whereas no biological agent was so. In $2003,46.7 \%$ respondents started treatment with DMARDs if RA was suspected (30.9\% in 1997); no one waited for erosions to occur $(7.3 \%$ in 1997).

Conclusion: The data obtained in this study suggest that the concept of diagnosing and treating RA early is accepted by a large proportion of the rheumatological community.
$\mathrm{R}$ heumatoid arthritis (RA) is a chronic and disabling disease with considerable socioeconomic impact. ${ }^{12}$ Drug treatment of RA comprises disease modifying antirheumatic drugs (DMARDs), glucocorticoids, and the symptom relieving non-steroidal anti-inflammatory drugs (NSAIDs); however, DMARDs are the most important component among these treatments. ${ }^{3}$ The strategies of DMARD employment have a rather multifarious history. ${ }^{4-6}$

RA is currently defined according to the American Rheumatism Association criteria, ${ }^{7}$ which have been derived from patients with long term, established disease. However, when it comes to early disease, no diagnostic criteria are available. Yet early and aggressive treatment of RA has become the most promising of the mentioned therapeutic strategies, as damage can be prevented, and sustained low disease activity or remission achieved..$^{8-13}$ Although all efforts have currently been made to fortify the evidence around this concept, the degree to which it is transposed and indeed established in daily practice remains uncertain. We therefore aimed at determining the awareness and application of this concept among rheumatologists, using three matched questionnaires distributed to rheumatologists and evaluated between 1997 and 2003.

\section{METHODS}

This survey is based on three consecutive questionnaires on early RA targeted at international rheumatologists. Table 1 shows the items included in the questionnaires, which can be categorised as follows: definition of early RA; referral time of potential patients with early RA; diagnostic means; follow up intervals; and treatment approaches. The initial questionnaire was handed out at the EULAR Symposium 1997. In 2000 an identical follow up questionnaire was sent to all original respondents who had indicated interest in the proceedings; the respective results have been reported. ${ }^{14}$
Finally, in 2003, all addressees of the year 2000 survey were sent an expanded version of the original questionnaire, which accounted for the changes in the therapeutic landscape (leflunomide and biological treatments) and new diagnostic approaches (antibodies directed to cyclic citrullinated peptide (anti-CCP)) (table 1). All three questionnaires were self completed.

All 85 respondents of the 1997 questionnaire who had provided their names and addresses received the follow up questionnaires in 2000 and 2003; 44 (52\%) and 46 (54\%) rheumatologists, respectively, responded. For the purpose of individual matching of the survey data, those 29 of the initial participants (34\%), who did not respond to any of the follow up questionnaires, were excluded from further analyses. An analysis including all respondents altered the numbers but not the trends that were seen in the matched analysis. However, we included participants with response to only one of the follow up surveys, because a matched analysis was possible among these. This gives a total of 56 original participants available for further analysis, of whom 12 had no matches in 2000, and 10 had none in 2003. Of the initial respondents, 94/111 (85\%) were trained rheumatologists, 9/111 (8\%) rheumatologists in training, 6/111 (6\%) nonrheumatological clinicians, and 2/111 (1\%) basic scientists. Their affiliations were Universities 59/111 (53\%), city hospitals $43 / 111$ (39\%), and private practices 9/111 (8\%). European countries accounted for 53/111 (48\%) of the respondents. This pattern of characteristics was similar for the responders of the follow up questionnaires.

Abbreviations: ACR, American College of Rheumatology; CCP, cyclic citrullinated peptide; DMARDs, disease modifying antirheumatic drugs; MTX, methotrexate; NSAID, non-steroidal anti-inflammatory drug; RA, rheumatoid arthritis; RF, rheumatoid factor 
Table 1 Items included in the questionnaires*

\begin{tabular}{|c|c|c|}
\hline Topic & Item(s) & Possible answers \\
\hline Definition & $\begin{array}{l}\text { What do you regard as early RA? } \\
\text { A. Type of arthritis (at least) } \\
\text { B. Duration of symptoms (one answer) }\end{array}$ & $\begin{array}{l}\text { A. At least: polyarthritis ( }>5 \text { joints)/oligoarthritis }(2-5 \text { joints) } / \text { monarthritis } \\
\text { B. } 6 \text { weeks } /<3 \text { months } /<6 \text { months/ } \\
<12 \text { months/other, please specify }\end{array}$ \\
\hline Referral time & $\begin{array}{l}\text { How long on average does it take from } \\
\text { onset of their symptoms until patients with } \\
\text { arthritis are referred to you? (one answer) }\end{array}$ & $<6$ Weeks $/<3$ months $/<6$ months $/<12$ months $/>12$ months \\
\hline Diagnostic approach & $\begin{array}{l}\text { Which serological tests do you use in the } \\
\text { context of early diagnosis? (several answers) }\end{array}$ & $\begin{array}{l}\text { Rheumatoid factor/antinuclear antibodies/antikeratin antibodies / } \\
\text { antiperinuclear factor/anti-RA33/anti-CCP (only in 2003) }\end{array}$ \\
\hline Follow up of patients & $\begin{array}{l}\text { How often do you see your patients with } \\
\text { early arthritis during the first } 3 \text { months? } \\
\text { (one answer) }\end{array}$ & Every 2 weeks/every month/every 3 months/not at all \\
\hline \multirow[t]{4}{*}{ Treatment } & $\begin{array}{l}\text { When do you start DMARD treatment in } \\
\text { patients with newly diagnosed RA? (one } \\
\text { answer) } \\
\text { In patients with newly diagnosed RA, } \\
\text { which DMARDs do you prescribe most } \\
\text { commonly? (maximum of two answers) }\end{array}$ & $\begin{array}{l}\text { When erosions have occurred/when ACR criteria are fulfilled/when } \\
\text { RA is suspected/when NSAIDs have failed }<12 \text { months/ }>6 \text { months/ } \\
>3 \text { months/other, please specify } \\
\text { Azathioprine/chloroquine/hydroxychloroquine/chlorambucil/ } \\
\text { cyclophosphamide/cyclosporin A/D-penicillamine/parenteral gold } \\
\text { compounds/oral gold compounds/methotrexate/sulfasalazine/other, } \\
\text { please specify } \\
\text { The following DMARDs were newly presented in the } 2003 \\
\text { questionnaire: leflunomide, infliximab, etanercept, anakinra, adalimumab }\end{array}$ \\
\hline & $\begin{array}{l}\text { Which DMARD do you currently use most } \\
\text { in your patients with RA? (please grade } \\
\text { as: } 1=\text { very commonly; } 5=\text { not at all) }\end{array}$ & Same DMARDs as above \\
\hline & $\begin{array}{l}\text { Do you use glucocorticoids regularly? } \\
\text { (several answers possible) }\end{array}$ & $\begin{array}{l}\text { Together with NSAIDs/as DMARDs without other DMARDs/ } \\
\text { together with other DMARDs/usually at }<10 \mathrm{mg} / \text { day/usually } \\
\text { at }>10 \mathrm{mg} / \text { day/for long periods/as short a period as possible }\end{array}$ \\
\hline & $\begin{array}{l}\text { When do you start glucocorticoids for } \\
\text { the first time? (several answers possible) }\end{array}$ & $\begin{array}{l}\text { At the time of diagnosis/if DMARDs have failed/as bridging } \\
\text { treatment until DMARDs work }\end{array}$ \\
\hline $\begin{array}{l}\text { Laboratory tests in } \\
\text { follow up of RA }\end{array}$ & $\begin{array}{l}\text { Which laboratory tests do you usually ask } \\
\text { for when following up your patients with } \\
\text { RA? (yes/no, frequency per year) }\end{array}$ & $\begin{array}{l}\text { ESR/CRP/serum amyloid A/rheumatoid factor/antinuclear antibodies/ } \\
\text { complete blood count/chemistry (liver, kidney,...)/others, please specify }\end{array}$ \\
\hline
\end{tabular}

The analyses were focused on temporal trends in the rheumatologists' perception of the early arthritis concept. Therefore opinions rather than biological variables have been assessed, and test statistics were dismissed. Data were registered and processed using the version 11.0 of the Statistical Package for the Social Sciences (SPSS, Chicago, IL).

\section{RESULTS}

\section{Clinical definition of early RA}

The American College of Rheumatology (ACR) criteria for classification of RA are derived from patients with established disease. ${ }^{15}$ Given the lack of criteria for classification of early RA, we asked the participants' opinion on some aspects related to early RA-namely, the number of affected joints and the duration of complaints (figs $1 \mathrm{~A}$ and $\mathrm{B}$ ). The proportion of rheumatologists requiring unequivocal polyarthritis (that is, six or more joints) for their definition of early RA decreased consistently and by exactly one third until 2003. The proportion demanding at least oligoarthritis (that is, more than two joints) was essentially stable $(61 \%, 59 \%$; $63 \%$ ) over the years. In contrast, arthritis in only one joint (that is, monarthritis) was increasingly considered as potential early RA—namely, by almost twice as many respondents in 2003 as in 1997 (17.4\% v 9.8\%, respectively; fig 1A).

Very stringent definitions for symptom duration ( $<6$ weeks) have been used by $23-26 \%$ of rheumatologists over time (fig 1B); however, the clinically more practicable threshold of 3 months (see paragraph on referral below) is increasingly part of the individual definitions of "early" RA (conceptually includes also the $<6$ weeks group: $65.5 \%$ in 1997 compared with $84.8 \%$ in 2003). Consequently, the fraction of rheumatologists accepting longer symptom durations decreased (fig 1B).

\section{Lag time of patient referral}

The proportion of rheumatologists who stated that they see patients within $<6$ weeks from symptom onset has almost doubled from $8.9 \%$ in the year 1997 to $17.4 \%$ in 2003 (fig 1C), while the total proportion indicating delays of referral of up to 3 months remained essentially unchanged. However, in $200317.4 \%$ of the rheumatologists indicated referral delays of more than 12 months on average; in the year 2000 this proportion was only $6.8 \%$.

Although their definition of early RA had changed with time, rheumatologists still saw similar numbers of patients with early RA during a year (table 2). This was the case for the total number of patients with RA cared for (median of 200), as well as for the number of patients with early RA (as defined above; median of 20/year). There was also no change in the median of the "average number of annual visits" of patients with RA as stated by the physicians, which was four at all times.

\section{Serological support for early diagnosis}

A variety of serological markers have been proposed for the diagnosis of early RA. We therefore presented the following commonly used measures to the participants ${ }^{76-20}$ : rheumatoid factor (RF), antinuclear antibodies, antikeratin antibodies, antiperinuclear factor, and anti-RA33. In the 2003 survey, tests for antibodies directed to anti-CCP were added ${ }^{21}$ according to their potential significance in establishing early diagnosis.

At all three times, RF was tested for by basically everyone to support the diagnosis of early RA (table 3). However, the 

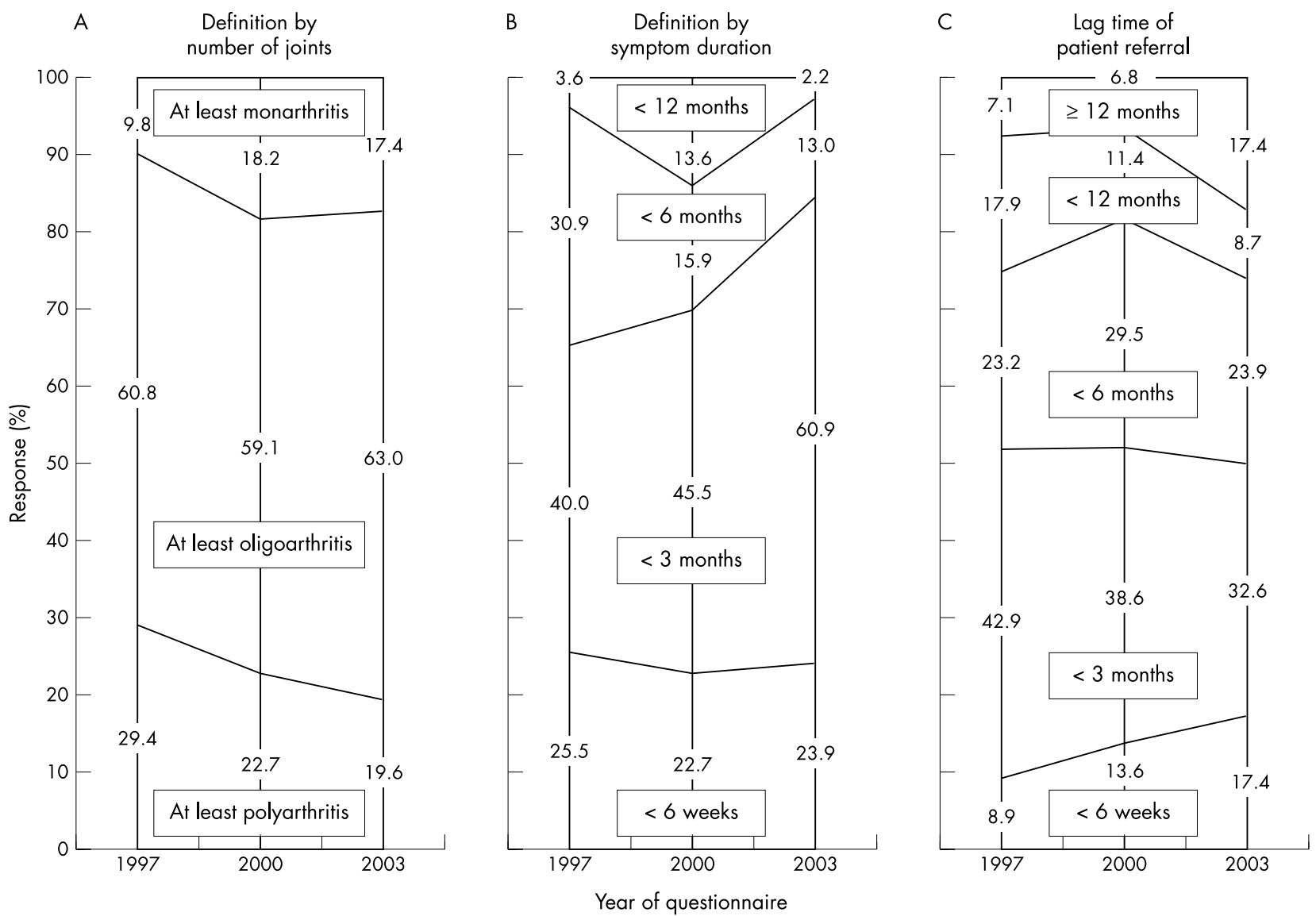

Figure 1 Cumulative presentation of opinions individually matched for responders to at least one of the follow up questionnaires between 1997 and 2003. The following questions were asked and allowed just one answer (total number of matched responders: $n=56 / 44 / 46$ for the years 1997/ 2000/2003): (A) What extent of arthritis do you at least require for a definition of early RA? (valid answers: $n=51 / 44 / 46$ ). (B) What maximum duration of symptoms do you still regard as early RA? (valid answers: $n=55 / 44 / 46$ ). (C) How long on average from onset of symptoms does it take until patients with arthritis are referred to you? (valid answers: $n=56 / 44 / 46$ ).

other measures offered were used infrequently, with the exception of the test for anti-CCP (in the 2003 questionnaire). Although tests for anti-CCP antibodies are the tests most recently introduced, they were already used by $17.4 \%$ for early diagnosis of RA.

\section{Frequency of follow up examinations in diagnosed early RA}

Apart from early introduction of DMARDs, close follow up of patients, especially in the initial phase, and rapid modification of the treatment regimen, if necessary, seem essential for eventual therapeutic success. ${ }^{22}$ Thus we also asked about the frequency of follow up examinations during the first 3 months after presentation (fig 2).

The fraction of rheumatologists performing very close follow up examinations, initially every 2 weeks, almost doubled within the observed 6 years from $16.1 \%$ to $30.4 \%$ (fig 2), while the proportion seeing their patients monthly decreased from 64.3 to $47.8 \%$. A stable $20 \%$ performed controls only every 3 months. This proportion did not change over the years. These data suggest that several of those rheumatologists who originally saw their patients with early RA monthly in 1997 have further increased the tightness of following up early RA.

\section{DMARD treatment in early RA}

Realisation of early treatment not only depends upon early referral and definition of symptom duration, but also upon the time in the disease course which rheumatologists regard as appropriate to start DMARD treatment. For example, in 1997, $7.3 \%$ of respondents to the survey stated that they would wait for evidence of bone erosions before starting a

Table 2 Patients seen at the different times by the rheumatologists (quartiles)

\begin{tabular}{llll}
\hline & $\begin{array}{l}\text { Quartiles of patients seen by rheumatologists (number of valid } \\
\text { responses) }\end{array}$ \\
\cline { 2 - 4 } & $1997(\mathbf{n = 5 6 )}$ & $\mathbf{2 0 0 0}(\mathbf{n = 4 4 )}$ & $\mathbf{2 0 0 3}(\mathbf{n = 4 6 )}$ \\
\hline Total No of patients with RA seen & $90 ; 200 ; 300(55)$ & $70 ; 150 ; 300(43)$ & $100 ; 200 ; 400(45)$ \\
Average number of annual visits & $3 ; 4 ; 6(50)$ & $3 ; 4 ; 4.5(43)$ & $2.5 ; 4 ; 5(46)$ \\
Patients with early RA seen & $10 ; 20 ; 35(55)$ & $10 ; 18 ; 50(43)$ & $10 ; 26 ; 40(45)$ \\
Percentage of patients with early RA & $5 ; 11.3 ; 20(54)$ & $7.7 ; 13.7 ; 20(42)$ & $6.9 ; 10 ; 16.3(44)$ \\
\hline
\end{tabular}




\begin{tabular}{|c|c|c|c|}
\hline & \multicolumn{3}{|c|}{$\%$ Responses in questionnaires } \\
\hline & $\begin{array}{l}1997 \\
(\mathrm{n}=54)\end{array}$ & $\begin{array}{l}2000 \\
(n=44)\end{array}$ & $\begin{array}{l}2003 \\
(n=46)\end{array}$ \\
\hline Rheumatoid factor & 100 & 100 & 97.2 \\
\hline Antinuclear antibodies & 72.2 & 68.2 & 78.3 \\
\hline Antikeratin antibodies & 5.6 & 9.1 & 8.7 \\
\hline Antiperinuclear factor & 13.0 & 9.1 & 8.7 \\
\hline Anti-RA33 & 3.7 & 6.8 & 2.2 \\
\hline Anti-CCP & NA & NA & 17.4 \\
\hline
\end{tabular}

NA, not available.

DMARD (fig 3, line A). In 2000 and 2003 no one did so. This affirmative trend is underlined by two other developments between 1997 and 2003: a decrease in the proportion of physicians who require fulfilment of the ACR criteria ${ }^{7}$ before starting DMARDs (fig 3, line B), and a substantial increase among those who start DMARDs upon mere suspicion rather than firm diagnosis of RA (fig 3, line C). Only $11-14 \%$ of the respondents would maintain NSAIDs for 3-6 months before starting a DMARD (fig 3, lines D and E).

Finally, the participants were also asked to make a choice of their favourite two DMARDs in early RA. The choices in the 2003 survey were supplemented with the newly introduced DMARDs: leflunomide, infliximab, etanercept, adalimumab, and anakinra. Figure 4 shows the proportions of responders who chose the different DMARDs. These are embedded in line graphs of DMARDs used in established RA to better judge the relative early use of the respective regimens. Early methotrexate (MTX) ranked first at all three time points, and in 2003 it was among the first two choices of every single respondent. MTX was followed, however, by a wide margin, by sulfasalazine, which was used by $52-66 \%$ of the participants. The use of antimalarial drugs had declined by about one third and parenteral gold compounds by about two thirds over the past 6 years; oral gold compounds, cyclosporin A, and chlorambucil were not used any more in 2003, while azathioprine was not at all used as first DMARD. From the choices of new therapeutic agents in the 2003 questionnaire (see table 1), only leflunomide was used (by $11 \%$ ) as first line DMARD in newly diagnosed patients (fig 4). The biological compounds were reserved for later stages of treatment, although their general rate of employment in RA was also rather small.

Examination of these changes in DMARD types and the timing of DMARD treatment in early RA has to be complemented by considering potential changes in treatment strategies with glucocorticoids. Most rheumatologists were using steroids as bridging treatment until DMARDs would work (percentages are given for the three times and are rounded for simplicity: 100\%/98\%/91\%). At the same time, about $40 \%$ stated that they were using steroids at the time of diagnosis of RA. This suggests that steroids do not have an essential role in the treatment of RA in the absence of DMARD treatment, which is further underlined by the decreased use of steroid (42\%/37\%/33\%) "as DMARD without other DMARDs". Further characteristics of steroid treatment found in this study are a decreasing use of higher $(>10 \mathrm{mg} /$ day) doses $(69 \% / 60 \% / 42 \%)$, and limiting treatment to be "as short as possible" $(98 \% / 91 \% / 83 \%)$.

\section{DISCUSSION}

By now the benefits of early and aggressive treatment of RA at an early stage are well supported,,$^{8-10} 23-28$ and a narrow opportunity for remission-targeting treatment has been claimed..$^{5-10}$ However, remission was uncommon in the

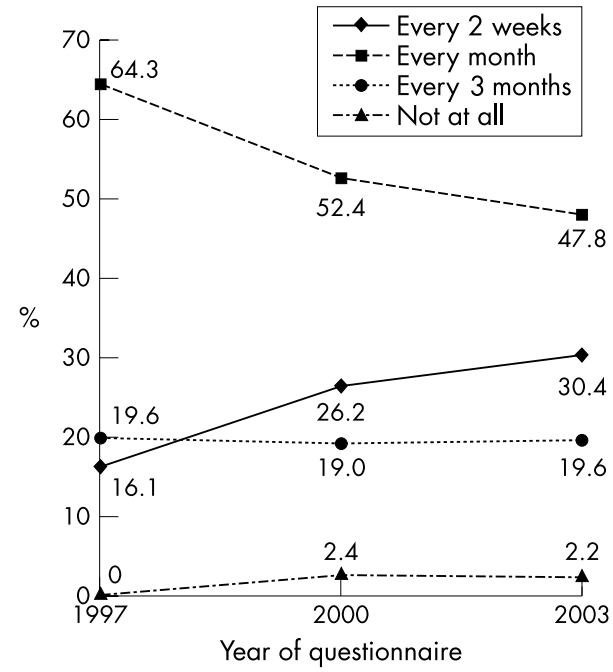

Figure 2 How often do you see your patients with early arthritis during the first 3 months? Individually matched opinions of responders to at least one of the follow up questionnaires between 1997 and 2003 are presented (total number of matched responders: $n=56 / 44 / 46$ for the years 1997/2000/2003; there were no missing data). Only the choice of one of the four time intervals was possible for each responder.

clinical trials of early RA, ${ }^{86-28}$ but structural consequences of delayed aggressive treatment became obvious from trial extension $^{29}$ and observational studies. ${ }^{10}$ Delays in the treatment of RA for a great part may be related to the lack of established criteria to classify or diagnose early RA (or to differentiate potentially destructive disease from other forms of early inflammatory arthritis). Although RA is usually classified according to the 1987 American Rheumatism

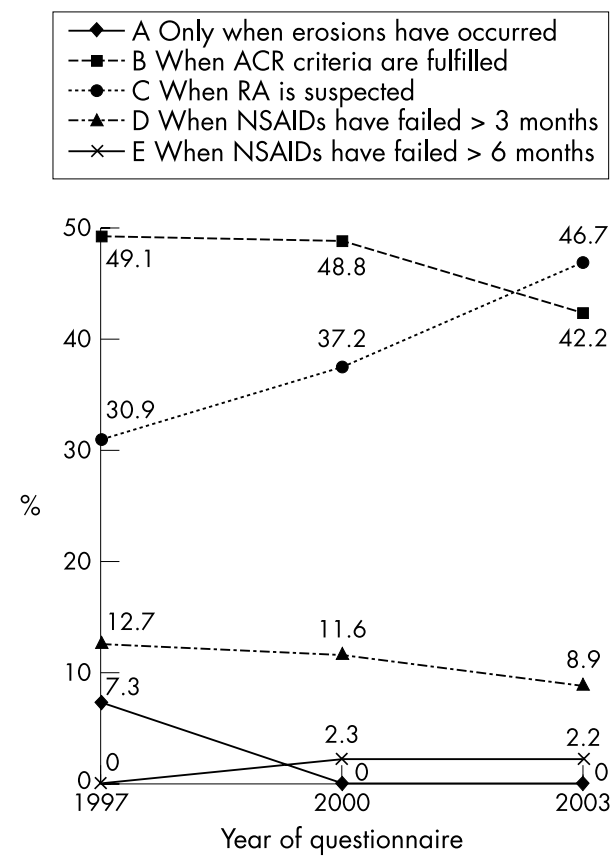

Figure 3 When do you start DMARD treatment in patients with newly diagnosed RA? Individually matched opinions of responders to at least one of the follow up questionnaires between 1997 and 2003 are presented (total number of matched responders: $n=56 / 44 / 46$ for the years 1997/2000/2003; valid answers: $n=55 / 43 / 45$ ). Only one choice out of six options (A-E) was possible for each responder. No responder picked the option: NSAID failure $>12$ months. 

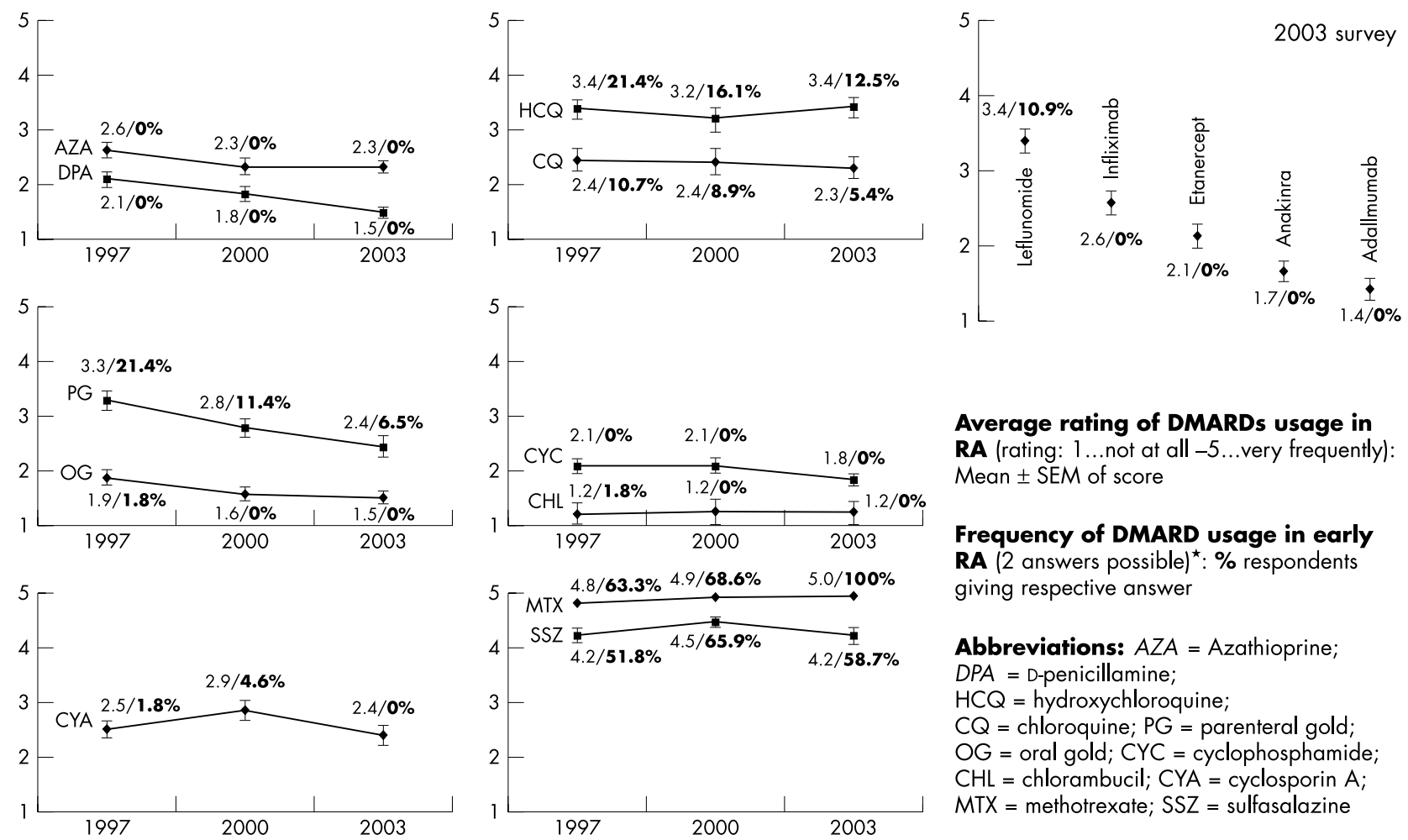

Average rating of DMARDs usage in

RA (rating: 1 ... not at all -5 ...very frequently): Mean \pm SEM of score

\section{Frequency of DMARD usage in early RA (2 answers possible) ${ }^{\star}: \%$ respondents giving respective answer}

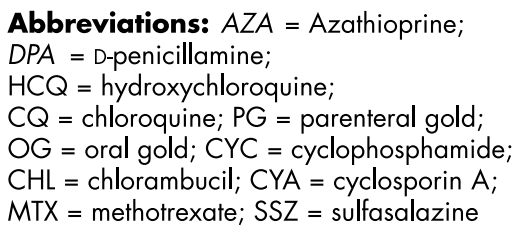

Figure 4 DMARD treatment in patients with established RA and early RA. Established RA: Lines present means (SEM) of valid answers on the frequency of DMARD usage in established RA (left score in legends); the rating scale ranged from " 1 " (not at all) to " 5 " (very frequently). Valid answers in $1997(n=56), 2000(n=44)$, and $2003(n=46)$ for the individual DMARDs given: 50-55/42-44/46. Early RA: Percentages given on right in legends refer to the proportion of responders who stated that they used the respective DMARD in early RA (two choices were allowed; however, percentages may not exactly add up to $200 \%$, because some responders gave only one answer). Valid responders: $55 / 44 / 46$.

Association criteria," classification of "early rheumatoid arthritis (RA)" is still an area of uncertainty. Therefore, in clinical trials of early arthritis broad ranges of disease duration (between 3 months and 5 years) or of joint involvement have been used. This heterogeneity may have been reflected also in daily practice, and consequently, the correct diagnosis and rapid institution of DMARDs been delayed. Nevertheless, when asked their opinions, the vast majority of the responding rheumatologists in this survey claimed to have a time frame of symptoms of $<3$ months for classifying early RA. This is in line with evidence that once arthritis persists for 12 weeks, the risk of a poor outcome is high. ${ }^{22}{ }^{30}$ Furthermore, also a majority of responding rheumatologists did not require the presence of polyarthritis in their personal definition of early RA, and for over $17 \%$ even involvement of a single joint was sufficient.

Serological tests, such as for RF, are central aids to diagnosis, and are used by most rheumatologists. Our data also indicate that new tools to support early diagnosis, such as a test for antibodies directed against cyclic citrullinated peptide (anti-CCP), ${ }^{21} 31$ are incorporated into daily care to some extent. This shows the interest of the rheumatological community in the transformation of new insights into clinical practice.

According to our data, very early referrals (patients with symptoms of $<6$ weeks) have become much more common, although late referrals ( $\geqslant 12$ months) have also become more frequent. Because long referral times are not fully under the control of the rheumatologist, these data call for the intensification of campaigns, targeting primary care and other referring physicians as well as the patients - that is, the population. In other words, the academically appealing and therefore very constringent cut off points are important, but reducing the commonly very long referral times by even a few weeks or months could lead to a further considerable reduction of the socioeconomic impact of RA.

Finally, important changes have been found for the individual preconditions of DMARD treatment: since the 2000 survey no rheumatologist waits for erosions to appear before starting a DMARD, and the number who start a DMARD upon simple suspicion of RA has increased considerably. The classification criteria for $\mathrm{RA}^{7}$ which have been derived from patients with longstanding disease, are not helpful in early diagnosis. ${ }^{13}{ }^{15}$ Apart from timing of DMARDs in early RA, the aggressiveness of treatment seems to have a pivotal role, ${ }^{27}{ }^{32}{ }^{33}$ which might be reflected in our study by the maximised used of MTX and the decline in employment of, especially, antimalarial drugs. In 2003, leflunomide overtook gold compounds in being used early on, while the biological agents were kept for later in the disease course. Additionally, almost $80 \%$ of rheumatologists followed up their patients every 2-4 weeks during the initial stage, allowing for rapid adaptation of treatment, which is essential to the concept of early treatment.

Despite the clear trends, the results of the interview may appear somewhat disappointing for the advocates of early diagnosis and treatment of RA. It may well be that implementation of this strategy is insufficient for logistical reasons regarding the late presentation of patients with early $\mathrm{RA}$; or because of controversy-that is, lack of conviction about the strategy of early diagnosis and treatment. We believe that the data do not suggest the latter, rather it appears as if implementation of the strategy is progressing, but changes of logistics and sufficient awareness in the public take their time. Also, the lack of classification criteria for early RA may hamper more rapid realisation of the concept.

In the report on the year 2000 questionnaire ${ }^{14}$ we discussed the potential drawbacks of surveys. However, contrary to 
questionnaires aimed at determining disease states-for example, the Health Assessment Questionnaire, validity of a survey like the present one, which targets opinions rather than the scientific "truth", will be less affected by selection bias. Nevertheless, as discussed previously, this survey is assumedly biased towards the selection of opinion leaders, for the following reasons: firstly, the initial recruitment was made at an international conference (the EULAR Symposium 1997; approximately 2000 participants); secondly, only a small proportion of these EULAR attendees participated; and, thirdly, by virtue of their participation they were more likely to have a special interest in the topic. On the other hand, the participants' origins indicate that this survey constitutes a good representation of the EULAR countries, although it is not representative for the number of their rheumatologists.

In conclusion, this study is characterised by the extensive diversity of the participants from all over the world as well as by the incorporation of $66 \%$ physicians who responded to the initial and at least one of the follow up questionnaires. The 6 year follow up provides profound insights into the realisation of the early arthritis concept, as now real temporal trends can be determined, which was not possible previously when opinion had been assessed at only two point. These trends are the essence of this study, as they might direct new actions, further research, and maybe behavioural adaptation among rheumatologists. Importantly, the data obtained provide evidence that the concept of diagnosing and treating RA early is increasingly permeating the rheumatological community.

\section{ACKNOWLEDGEMENTS}

We are indebted to the participants of all questionnaires. In particular, we acknowledge the following responders (affiliations in parentheses): P Airò, MD (Servizio di Immunologia Clinica Brescia, Italy); F Akinci, MD, Prof. (University of Hacettepe, Ankara, Turkey); S Bachmann, MD. (Valens, Switzerland); G Balint, MD, FRCP, DSC (National Institute of Rheumatology and Physiotreatment, Budapest, Hungary); U Botzenhardt, MD (Rotes Kreuz Krankenhaus, Bremen, Germany); M Catita, MD (Bairro de Belem, Lisboa, Portugal); N Chichasova, MD, Prof. (Institute of Rheumatology, Moscow, Russia); G Eszenki, MD (Özd Városi Önkormányzat, Hungary); Z Fojtik, MD (University Hospital, Brno, Czech Republic); I Gao, MD (Klinik für Rheumakranke, Bad Kreuznach, Germany); J Gibson, BSc, MBChB, MD (Cameron Hospital, Windygates, United Kingdom); I Grigortchouk, MD (Minsk State Medical Institute, Ukraine); L Grövle, MD (Östfold Sentral Sykehus, Sarpsborg, Norway); I Günaydin, MD (Department of Rheumatology and Immunology, Tübingen, Germany); C Haagsma, MD, PhD (Medisch Spectrum Twente, Enschede, The Netherlands); T Hansen, MD (KAS Herlev, Denmark); Z Hrncir, MD, Prof. (Charles University Hradec Králové, Czech Republic); A Insperger, MD (Veszprem, Hungary); A Karjalainen, MD (University Hospital Oulu, Finland); A Kavanaugh, MD (Southwestern Medical Center, University of Texas, Dallas, USA); M Kos-Golja, MD (University Medical Centre, Ljubljana, Slovenia); I Kötter, MD (Department of Rheumatology, University of Tübingen, Germany); A Larsen, MD (Kongsvinger Central Hospital, Norway); G Lüdemann, MD (Ostseeklinik Damp, Germany); B Masri, MD (Amman, JORDAN); P Morassi, MD (Trieste, Italy); S Mulic-Bacic, MD, PhD (University Clinical Centre Tuzla, Bosnia Herzegovina); Y Mouraviev, MD, Prof. (Institute of Rheumatology of RAMS, Moscow, Russia); F Niksic, MD (Salzburg County Hospital, Austria); V Petric, MD (Murska Sobota General Hospital, Slovakia); J Riutort Gayá, MD (Policlinica Miramar, Palma de Mallorca, Spain); H Seleskovic, MD, PhD, Prof. (University Clinical Centre Tuzla, Bosnia Herzegovina); C Sengupta, MD (St Gallen, Switzerland); V Shishkin, MD, Prof. (St Petersburg, Russia); S Sørensen, MD (Bispebjerg Hospital, Copenhagen, Denmark); C Specker, MD (MNR Klinik Düsseldorf, Germany); R Stojanovic, MD, PhD (Belgrade, Yugoslavia); U Stuby, MD (Linz County Hospital, Austria); L Szczepanski, MD, Prof. (Lubin, Poland); L Tamasi, MD (University Hospital Miskolc, Hungary); E Theander, MD (University Hospital Malmö, Sweden); T Uutela, MD (Rovaniemi, Finland); P Williams, MD, FRCP (Medway Hospital, Gillingham, United
Kingdom); U Yli-Kerttula, MD (Tampere University Hospital, Pikonlinna, Finland).

\section{Authors' affiliations}

D Aletaha, V P K Nell, K P Machold, J S Smolen, Division of

Rheumatology, Department of Internal Medicine III, University of Vienna, Vienna, Austria

G Eberl, J S Smolen, Second Department of Medicine, Lainz Hospital and Ludwig Boltzmann Institute for Rheumatology, Vienna, Austria

\section{REFERENCES}

1 Wolfe F. The natural history of rheumatoid arthritis. J Rheumatol Suppl 1996:44:13-22.

2 Yelin E, Wanke LA. An assessment of the annual and long-term direct costs of rheumatoid arthritis: the impact of poor function and functional decline. Arthritis Rheum 1999;42:1209-18.

3 Smolen JS, Steiner G. Therapeutic strategies for rheumatoid arthritis. Nat Rev Drug Discov 2003;2:473-88.

4 Fries JF. Reevaluating the therapeutic approach to rheumatoid arthritis: the "sawtooth" strategy. J Rheumatol Suppl 1990;22:12-15.

5 O'Dell JR. The therapeutic pyramid: a work in progress. J Rheumatol 1997; 24:1028-30.

6 Wilske KR, Healey LA. Remodeling the pyramid-a concept whose time has come. J Rheumatol 1989;16:565-7.

7 Arnett FC, Edworthy SM, Bloch DA, McShane DJ, Fries JF, Cooper NS, et al. The American Rheumatism Association 1987 revised criteria for the classification of rheumatoid arthritis. Arthritis Rheum 1988;31:315-24

8 van der Heide A, Jacobs JW, Biilsma JW, Heurkens AH, Booma-Frankfort C, van der Veen MJ, et al. The effectiveness of early treatment with "second-line" antirheumatic drugs. A randomized, controlled trial. Ann Intern Med 1996; 124:699-707.

9 Nell VPK, Machold KP, Eberl G, Stamm T, Uffmann M, Smolen JS. The Benefit of very early referral and therapy with disease modifying antirheumatic drugs in patients with early rheumatoid arthritis [abstract]. Arthritis Rheum 2002;46(suppl 9):S334.

10 Bukhari MA, Wiles NJ, Lunt M, Harrison BJ, Scott DG, Symmons DP, et al. Influence of disease-modifying therapy on radiographic outcome in inflammatory polyarthritis at five years: results from a large observational inception study. Arthritis Rheum 2003;48:46-53.

11 Emery P, Salmon M. Early rheumatoid arthritis: time to aim for remission? Ann Rheum Dis 1995;54:944-7.

12 Lard LR, Visser H, Speyer I, vander Horst-Bruinsma IE, Zwinderman AH, Breedveld FC, et al. Early versus delayed treatment in patients with recentonset rheumatoid arthritis: comparison of two cohorts who received different treatment strategies. Am J Med 2001;111:446-51.

13 Machold KP, Stamm TA, Eberl GJ, Nell VK, Dunky A, Uffmann M, et al. Very recent onset arthritis - clinical, laboratory, and radiological findings during the first year of disease. J Rheumatol 2002;29:2278-87.

14 Aletaha D, Eberl G, Nell VP, Machold KP, Smolen JS. Practical progress in realisation of early diagnosis and treatment of patients with suspected rheumatoid arthritis: results from two matched questionnaires within three years. Ann Rheum Dis 2002;61:630-4.

15 Silman AJ, Symmons DP. Selection of study population in the development of rheumatic disease criteria: comment on the article by the American College of Rheumatology Diagnostic and Therapeutic Criteria Committee. Arthritis Rheum 1995; 38:722-3.

16 Waaler $\mathbf{E}$. On the occurrence of a factor in human serum activating the specific agglutination of sheep blood corpuscles. Acta Pathol Microbiol Scand 1940;17:172-88.

17 Vincent C, Serre G, Lapeyre F, Fournie B, Ayrolles C, Fournie A, et al. High diagnostic value in rheumatoid arthritis of antibodies to the stratum corneum of rat oesophagus epithelium, so-called 'antikeratin antibodies'. Ann Rheum Dis 1989;48:712-22.

18 Janssens X, Veys EM, Verbruggen G, Declercq L. The diagnostic significance of the antiperinuclear factor for rheumatoid arthritis. J Rheumatol 1988; 15:1346-50.

19 Hassfeld W, Steiner G, Graninger W, Witzmann G, Schweitzer H, Smolen JS. Autoantibody to the nuclear antigen RA33: a marker for early rheumatoid arthritis. Br J Rheumatol 1993;32:199-203.

20 Simon M, Girbal E, Sebbag M, Gomes-Daudrix V, Vincent C, Salama G et al. The cytokeratin filament-aggregating protein filaggrin is the target of the so-called "antikeratin antibodies," autoantibodies specific for rheumatoid arthritis. J Clin Invest 1993;92:1387-93.

21 Schellekens GA, Visser $H$, de Jong BA, van den Hoogen FH, Hazes JM, Breedveld FC, et al. The diagnostic properties of rheumatoid arthritis antibodies recognizing a cyclic citrullinated peptide. Arthritis Rheum 2000;43:155-63.

22 Proudman SM, Conaghan PG, Richardson C, Griffiths B, Green MJ McGonagle D, et al. Treatment of poor-prognosis early rheumatoid arthritis. A randomized study of treatment with methotrexate, cyclosporin $A$, and intraarticular corticosteroids compared with sulfasalazine alone. Arthritis Rheum 2000;43:1809-19.

23 Egsmose C, Lund B, Borg G, Pettersson H, Berg E, Brodin U, et al. Patients with rheumatoid arthritis benefit from early 2 nd line therapy: 5 year followup of a prospective double blind placebo controlled study. J Rheumatol 1995;22:2208-13. 
24 Tsakonas E, Fitzgerald AA, Fitzcharles MA, Cividino A, Thorne JC, $M^{\prime}$ Seffar $A$, et al. Consequences of delayed therapy with second-line agents in rheumatoid arthritis: a 3 year followup on the hydroxychloroquine in early rheumatoid arthritis (HERA) study. J Rheumatol 2000;27:623-9.

25 Anderson JJ, Wells G, Verhoeven AC, Felson DT. Factors predicting response to treatment in rheumatoid arthritis: the importance of disease duration. Arthritis Rheum 2000;43:22-9

26 Bathon JM, Martin RW, Fleischmann RM, Tesser JR, Schiff MH, Keystone EC, et al. A comparison of etanercept and methotrexate in patients with early rheumatoid arthritis. N Engl J Med 2000;343:1586-93.

27 Boers M, Verhoeven AC, Markusse HM, van de Laar MA, Westhovens R, van Denderen JC, et al. Randomised comparison of combined step-down prednisolone, methotrexate and sulphasalazine with sulphasalazine alone in early rheumatoid arthritis. Lancet 1997;350:309-18.

28 Mottonen $T$, Hannonen $P$, Leirisalo-Repo $M$, Nissila $M$, Kautiainen $H$, Korpela $M$, et al. Comparison of combination therapy with single-drug therapy in early rheumatoid arthritis: a randomised trial. FIN-RACo trial group. Lancet 1999;353:1568-73.
29 Landewe RB, Boers M, Verhoeven AC, Westhovens R, van de Laar MA, Markusse HM, et al. COBRA combination therapy in patients with early rheumatoid arthritis: long-term structura benefits of a brief intervention. Arthritis Rheum 2002;46:347-56.

30 Harrison B, Symmons D. Early inflammatory polyarthritis: results from the Norfolk Arthritis Register with a review of the literature. II. Outcome at three years. Rheumatology (Oxford) 2000;39:939-49.

31 Visser H, le Cessie S, Vos K, Breedveld FC, Hazes JM. How to diagnose rheumatoid arthritis early: a prediction model for persistent (erosive) arthritis. Arthritis Rheum 2002;46:357-65.

32 Verstappen SM, Jacobs JW, Bijlsma JW, Heurkens AH, Booma-Frankfort C, Borg EJ, et al. Five-year followup of rheumatoid arthritis patients after early treatment with disease-modifying antirheumatic drugs versus treatment according to the pyramid approach in the first year. Arthritis Rheum 2003;48:1797-807

33 Boers M. Understanding the window of opportunity concept in early rheumatoid arthritis. Arthritis Rheum 2003;48:1771-4.

\section{Clinical Evidence-Call for contributors}

Clinical Evidence is a regularly updated evidence based journal available worldwide both as a paper version and on the internet. Clinical Evidence needs to recruit a number of new contributors. Contributors are health care professionals or epidemiologists with experience in evidence based medicine and the ability to write in a concise and structured way.

\section{Currently, we are interested in finding contributors with an interest in} the following clinical areas:

Altitude sickness; Autism; Basal cell carcinoma; Breast feeding; Carbon monoxide poisoning; Cervical cancer; Cystic fibrosis; Ectopic pregnancy; Grief/bereavement; Halitosis; Hodgkins disease; Infectious mononucleosis (glandular fever); Kidney stones; Malignant melanoma (metastatic); Mesothelioma; Myeloma; Ovarian cyst; Pancreatitis (acute); Pancreatitis (chronic); Polymyalgia rheumatica; Post-partum haemorrhage; Pulmonary embolism; Recurrent miscarriage; Repetitive strain injury; Scoliosis; Seasonal affective disorder; Squint; Systemic lupus erythematosus; Testicular cancer; Varicocele; Viral meningitis; Vitiligo However, we are always looking for others, so do not let this list discourage you.

\section{Being a contributor involves:}

- Appraising the results of literature searches (performed by our Information Specialists) to identify high quality evidence for inclusion in the journal.

- Writing to a highly structured template (about 2000-3000 words), using evidence from selected studies, within 6-8 weeks of receiving the literature search results.

- Working with Clinical Evidence Editors to ensure that the text meets rigorous epidemiological and style standards.

- Updating the text every eight months to incorporate new evidence.

- Expanding the topic to include new questions once every 12-18 months.

If you would like to become a contributor for Clinical Evidence or require more information about what this involves please send your contact details and a copy of your CV, clearly stating the clinical area you are interested in, to Claire Folkes (cfolkes@bmigroup.com).

\section{Call for peer reviewers}

Clinical Evidence also needs to recruit a number of new peer reviewers specifically with an interest in the clinical areas stated above, and also others related to general practice. Peer reviewers are health care professionals or epidemiologists with experience in evidence based medicine. As a peer reviewer you would be asked for your views on the clinical relevance, validity, and accessibility of specific topics within the journal, and their usefulness to the intended audience (international generalists and health care professionals, possibly with limited statistical knowledge). Topics are usually 2000-3000 words in length and we would ask you to review between 2-5 topics per year. The peer review process takes place throughout the year, and our turnaround time for each review is ideally 10-14 days.

If you are interested in becoming a peer reviewer for Clinical Evidence, please complete the peer review questionnaire at www.clinicalevidence.com or contact Claire Folkes(cfolkes@bmigroup.com). 